vasomotor control or neuromuscular mechanisms in the upper renal tract. This may explain the increased renal mortality associated with cord lesions at or above T11.

TABLE v-External, Radiological, and Sensory Levels in Children Dying of Renal Causes

\begin{tabular}{|c|c|c|c|}
\hline Case No. & Cutaneous Level & Dysraphic Vertebrae & Sensory Level \\
\hline $\begin{array}{l}1 \\
2 \\
3 \\
4 \\
5 \\
6 \\
7\end{array}$ & $\begin{array}{l}\text { Thoracolumbosacral } \\
\text { Lumbosacral } \\
\text { Lumbosacral } \\
\text { Lumbosacral } \\
\text { Lumbosacral } \\
\text { Lumbosacral } \\
\text { Thoracolumbosacral }\end{array}$ & $\begin{array}{l}\text { T12 - sacrum } \\
\text { L2 } \text { sacrum } \\
\text { T4-T12, L2 - sacrum } \\
\text { L1 = sacrum } \\
\text { L1 Z sacrum } \\
\text { L1 Z sacrum } \\
\text { T7 - sacrum }\end{array}$ & $\begin{array}{l}\text { T10 } \\
\text { T10 } \\
\text { T9 } \\
\text { T11 } \\
\text { T10 } \\
\text { T10 } \\
\text { T6 }\end{array}$ \\
\hline $\begin{array}{l}\text { Died since } \\
\text { survey began: } \\
8 \\
9\end{array}$ & $\begin{array}{l}\text { Thoracolumbar } \\
\text { Thoracolumbosacral }\end{array}$ & $\begin{array}{l}\text { T1 } \\
\text { T11 - sacrum } \\
\text { sacrum }\end{array}$ & $\begin{array}{l}\text { T8 } \\
\text { T10 }\end{array}$ \\
\hline
\end{tabular}

\section{Conclusions}

It is clear that in deciding whether or not to advise surgery no single criterion is going to suffice. The age and competence of the parents and their wishes in the matter, the number of children in the family, and the availability of specialist medical services and appropriate educational and training facilities must all play a part in the decision. But the fundamental question of the possibility of achieving a reasonable degree of independence is governed almost totally by the neurological deficit. In assessing this we wish to emphasize the importance of the sensory level.

We would like to thank the paediatricians in the East Anglian Region as well as many other paediatricians, medical officers of health, and general practitioners for their help in providing much of the information on which this report is based. We are also indebted to the many school-teachers, psychologists, and physiotherapists in the region who gave invaluable help with the disability assessments. Our thanks are due to Dr. E. C. Poulton, of the Medical Research Council, for doing the statistics, to Mrs. Sheldon for the figures, and to $\mathbf{M r}$. A. E. Holmes and Mr. A. H. G. Murley for advice in the preparation of this paper.

This research was carried out with financial support from the East Anglian Regional Hospital Board and The United Cambridge Hospitals.

APPENDIX-Lorber's (1972) Adverse Criteria Related to Sensory Level in 79 Cases

\begin{tabular}{|c|c|c|c|}
\hline \multirow[b]{2}{*}{ Adverse Criteria } & \multicolumn{3}{|c|}{ Sensory Level } \\
\hline & $\underset{(\mathbf{n}=33)}{\text { High }}$ & $\begin{array}{c}\text { Intermediate } \\
(\mathbf{n}=28)\end{array}$ & $\stackrel{\text { Low }}{(n=18)}$ \\
\hline 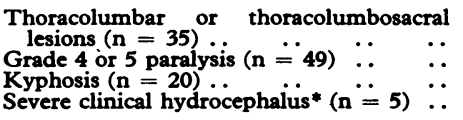 & $\begin{array}{r}27 \\
31 \\
19 \\
2\end{array}$ & $\begin{array}{r}7 \\
16 \\
1 \\
2\end{array}$ & $\begin{array}{l}1 \\
2 \\
0 \\
1\end{array}$ \\
\hline
\end{tabular}

* Severe clinical hydrocephalus as defined by Lorber indicates a head circumference at least $2 \mathrm{~cm}$ greater than the 90th centile using O'Neill's norms.

\section{References}

Brocklehurst, G., Gleave, J. R. W., and Lewin, W. S. (1967). British Medical Fournal, 1, 666 .

Egan, Dorothy F., Illingworth, R. S., and MacKeith, R. C. (1969). Developmental Screening 0-5 years. London, Heinemann.

mental Screening $0-5$ years. London, Heinemann.
Hamilton, W. J. (1966). Textbook of Anatomy. London, Macmillan. Hamilton, W. J. (1966). Textbook of Anatomy. London, Macmillan.

Lorber, J. (1971) Developmental Medicine and Child Neurology, 13, 279.

Lorber, J. (1972). Archives of Disease in Childhood, 47, 854.

O'Neill, Eileen M. (1961). Archives of Disease in Childhood, 36, 241

Porter, R. W. (1967). Developmental Medicine and Child Neurology, Suppl. No. 15 , p. 62 .

Sheridan, Mary D. (1960). Developmental Progress in Infants and Young Children. London, H.M.S.O.

Smith, E. Durham, and Smith, G. Keys. (1973). To be published.

Stark, G. D., and Drummond, Margaret, G. (1973). Archives of Disease in Childhood. In press.

\title{
Early Results of Selective Treatment of Spina Bifida Cystica
}

\section{J. LORBER}

British Medical fournal, 1973, 4, 201-204

\section{Summary}

The results of a policy of "selection" in treating infants with spina bifida cystica over 21 months are presented. Of 37 newborn infants referred on the first day of life 25 were not treated because of the severity of their condition, as defined by exact criteria. All died under 9 months of age. In contrast, only one treated infant died and the rest are either normal or moderately handicapped. Selection for treatment is offered as the best but not a good solution to an insoluble problem.

\section{Introduction}

Two major revolutions have occurred in the past 15 years in

\footnotetext{
Department of Child Health, University of Sheffield, Sheffield S10 2TH

J. LORBER, M.D., F.R.C.P., Reader in Child Health
}

the treatment of myelomeningocele. The first was the enthusiasm or moral compulsion to treat all infants, irrespective of the degree of their handicap-largely the result of the insistence of the Sheffield team (Sharrard et al., 1963; Zachary, 1968). The main reason for this enthusiasm was the introduction of the ventriculoatrial shunt in 1958. This procedure was able to control hydrocephalus effectively for the first time.

The second event was the disillusionment which occurred because the technical advances, especially the use of unidirectional valve systems to control the associated hydrocephalus, led to hopes that were unfortunately not fulfilled. Analysis of the results (Lorber, 1971; 1972 a) have shown that treating all infants still resulted in a high mortality rate in those cases severely affected at birth and yet led to the prolonged survival of many severely handicapped children, with gross paralysis, multiple deformities of the legs, fractures, kyphosis, scoliosis, incontinence of urine and faeces with frequent secondary effects of hydronephrosis, chronic pyelonephritis, and arterial hypertension. Hydrocephalus was usually well controlled with shunt therapy-in those who needed operation-but the complications of shunt therapy are exitremely common, requiring repeated operations. The mortality rate from these complications alone was $20 \%$ within seven years of the first shunt operation in a large group of 
children. Over half of the shunt-treated survivors were mentally handicapped and very few had an I.Q. over 100. At best not more than $10 \%$ of all the survivors (with and without hydrocephalus) were likely to have a chance of earning a living in competitive employment.

The survival of so many severely handicapped children gave rise to progressively greater anxiety among doctors, nurses, parents, teachers, and the general public. This became evident with the rising tide of comments on television, radio, in newspapers, and other media. The ethical validity of prolongation of profoundly handicapped lives, consisting of frequent operations, hospital admissions, and absence from home and school and with no prospect of marriage or employment, became less and less tenable. The cost of maintaining each such child is now about $£ 3,000$ a year. A change in policy was bound to come.

Though most infants were offered active treatment during the 1960's this practice was not universal, but those who did not treat all patients or were reluctant to do so did not repont their views or results until recently. Nevertheless, in Oxford (Hide et al., 1972) and in Edinburgh (Stark and Drummond, 1973) a policy of selection was carried out and, though exact criteria were not laid down where the line should be drawn, very few selectively untreated infants survived to two years of age and the condition of these survivors was probably no worse than if they had been treated. In Stark and Drummond's (1973) treated patients the condition of the survivors was more favourable than in those series in which all patients were treated without selection. A policy of selection was also practised in the large spina bifida clinic in Melbourne (Medical fournal of Australia, 1971), where a complex system of criteria were laid down and which were similar to those proposed in England in th: past two years (Lorber, 1971).

In my experience a detailed correlation between the physical findings soon after birth and the results of therapy has clearly indicated that it is possible to define a line of division as criteria for treatment. No infant among 400 consecutive cases treated from the first day of life who had any one or any combination of the adverse features shown in the appendix survived with less than very severe combined handicaps, while in the absence of these criteria many children survived with only "moderate" handicaps. Only half of the latter were treated with a shunt, their average intelligence was normal, and they had far fewer operations. Only $16 \%$ without adverse criteria died by 7 years compared with $59 \%$ of those with adverse criteria. In view of the predictability of the minimal likely handicap, I proposed, first at the 14th Annual General Meeting of the Society for Research in Hydrocephalus and Spina Bifida in Freiburg in 1970, that these criteria should be adopted for selection. The publication of these results (Lorber, 1971; 1972 a) led to the second revolution in the management of myelomeningocele-namely, an almost universal acceptance of selection* which has been officially recognized as legitimate practice (D.H.S.S., 1973). Selection is now being practised in some of the largest unitsfor example, at the Queen Mary's Hospital, Carshalton (Collis, 1972), and at the Hospital for Sick Children (Eckstein, 1973). There has been no difficulty with the nursing staff, who fully understand the humane purpose and the need for such practice, so long as they are taken into the confidence of the medical staff.

\section{Present Investigation}

This study describes the experiences and results of a policy of selection.based on the proposed line of division (see appendix) and examines the validity of this dividing line. In the

* Personal communications from most paediatricians and paediatric surgeons in Britain. current investigation it was necessary only to use the criteria for selection which were present at birth.

\section{Patients and Methods}

Between May 1971, when my policy of "selection" was put into practice, and 31 January 1973, 37 newborn infants born with spina bifida cystica were referred to the medical paediatric unit for assessment, and for treatment if thought appropriate. The infants were born either in the Jessop Hospital, in our own maternity unit (seven cases), or were referred by consultant paediatricians in the region who used to refer cases of spina bifida to the Combined Clinic of the Children's Hospital in the past (30 cases).

All the infants were assessed fully from every point of view. This included a full orthopaedic assessment by $\mathrm{Mr} W$. J. W. Sharrard or members of his staff. The decision whether to treat or not was entirely that of the paediatric team. If any infant had one or more of the "adverse criteria" (see appendix) as described earlier (Lorber, 1972 a) the father or both parents were interviewed by me (or in my absence by my senior assistant) in the presence of a member of the junior medical staff and a member of the nursing staff.

The infant's condition was fully explained and the facts were repeated, so as to leave no doubt in the parent's minds. The many possible therapeutic actions were described to them and a prognosis was given as to the likely minimal handicap their child might have if he was offered total treatment and if everything went well. The risks and possible complications were also explained without bias. Finally, a recommendation was made together with an offer for a second opinion. The interview took up to two hours and, if necessary, was repeated later.

No parent was asked to sign a consent form for operation without fully understanding what it would mean to the infant and the family. All but one couple accepted the doctor's recommendation. In one instance where the infant's condition was near the borderline treatment was advised, but the parents refused to give permission. The infant died shortly afterwards.

Several paediatricians in the region accepted the principle of selection and did not send those infants who had adverse criteria to the Children's Hospital. These included eight born in Sheffield, all of whom died very quickly. Partly as a result of this new policy a substantially smaller number of infants was referred to the hospital, and not all who were referred were treated.

\section{Results}

Active treatment was recommended for and accepted by the parents of 12 infants. Twenty-five were not treated.

\section{TREATED INFANTS}

Of the 12 treated infants 11 had no adverse criteria on admission, but one had a large thoracolumbosacral lesion. At examination within an hour of birth this infant had normal power in her legs, had no outward deformity, her head was of normal size, and the fontanelle was of normal tension. It was such a "good baby" that in spite of the size of her lesion operation was advised and closure of the back was carried out at 4 hours of age. Soon afterwards she lost practically all power in her legs. An intravenous pyelogram and micturating cystourethrogram showed gross hydronephrosis. An $x$-ray picture of her spine disclosed hemivertebrae at the thoracolumbar junction. This led to progressive scoliosis by 1 year of age. Severe progressive hydrocephalus gradually became apparent. This was treated successfully with isosorbide (Lorber, 1972 b). 
There was progressive deterioration in her renal condition and function studies showed little renal reserve. Thus the size and site of her spina bifida was an accurate prognostic sign, yet had she not been operated on at an early stage the gross loss of muscle function and her other problems might well have been attributed to failure of treatment.

The remaining 11 patients' spina bifida was upper thoracic (1), lumber (1), low lumbosacral (6), and sacral (3). One treated infant died on the surgical ward from respiratory arrest on the second day of life. This infant had no paralysis or hydrocephalus, but at necrosy an exceptionally large Arnold-Chiari malformation was found. All the remaining 10 infants are alive and are between 5 and 18 months of age at the time of writing. None have severe sequelae (Lorber, 1971) (table I). Three are fully normal. Seven have slight paraplegia but four of these pass a normal stream of urine and have good anal tone. Three have dribbling incontinence and patulous anus as well as having mild paraplegia.

TABLE I-Condition of 12 Treated Infants

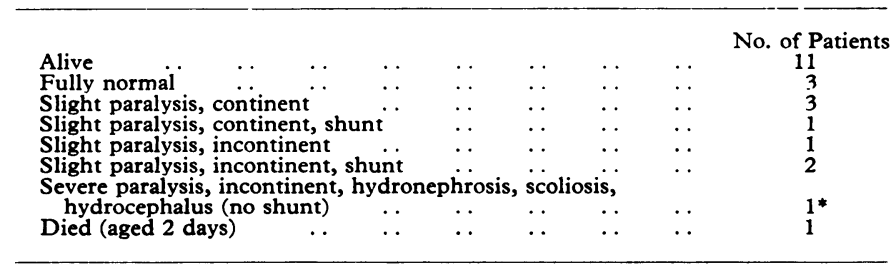

*The only child who had adverse criteria (thoracolumbosacral lesion) at birth.

Four of the 11 survivors have no hydrocephalus, two had moderate hydrocephalus which required no treatment, two other infants' moderate hydrocephalus was fully controlled with isosorbide, and the remaining three have shunttreated hydrocephalus (table II). None have an abnormally large head. None have required a revision of shunt treatment, so far. All have normal milestones of development.

TABLE II-Incidence of Hydrocephalus in 11 Surviving Treated Infants

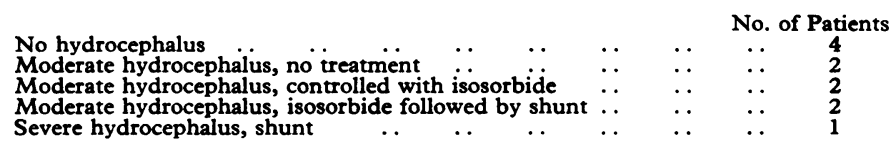

The 12 treated infants had 16 operations, including the primary closure, three shunt operations, and one foot correction during a total of 160 months of observation.

\section{UNTREATED INFANTS}

One infant had no adverse criteria, though she had moderately severe asymmetrical paraplegia, was incontinent, and had hydrocephalus. After much discussion with both parents they decided against treatment and the infant died at home under 1 month of age. The parents later wrote a thoughful and appreciative letter to The Times (1972). Most patients (21 out of 25) had two or more adverse criteria (table III). These consisted mostly of gross paralysis (24) and thoracolumbosacral lesions (20), but clinical kyphosis or scoliosis was also very common (13) (table IV). Intravenous pyelography and echoencephalography was carried out as a routine.

Once a decision was made not to treat these infants they were looked after as normal babies, given normal nursing-care, and were fed on demand. Analgesics were given as required, TABLE III-Number of "Adverse Criteria" on Admission in 25 Untreated
Patients

\begin{tabular}{|c|c|c|c|c|c|c|c|}
\hline & & & & & & & No. of Patients \\
\hline No adverse criteria* ${ }^{*} .$. & . & $\cdots$ & . & . & .. & . & $\ldots 1$ \\
\hline Only one adverse criteria & . & $\cdots$ & . & . & $\cdots$ & . & . \\
\hline Two adverse criteria & . & $\cdots$ & . & . & $\cdots$ & . & . \\
\hline $\begin{array}{l}\text { Three adverse criteria } \\
\text { Four adverse criteria }\end{array}$ & $\cdots$ & $\cdots$ & . & . & $\cdots$ & . & $\cdots$ \\
\hline Four adverse criteria & $\cdots$ & $\cdots$ & .. & $\cdots$ & $\cdots$ & . & . \\
\hline
\end{tabular}

*Parents refused treatment.

TABLE IV-“Adverse Criteria" on Admission in 25 Untreated Patients

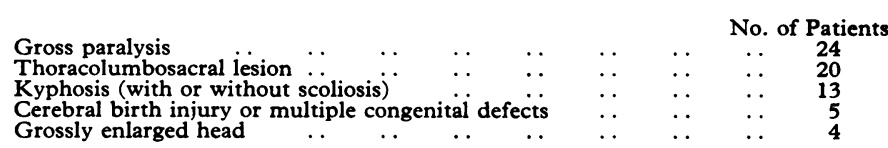

but no other treatment was offered: no oxygen, tube feeding, antibiotic drugs, or resuscitation. No painful investigations were carried out: no ventriculography, blood tests, etc. The parents could take the infant home (including for weekends), but they were not expected to do so. Infants born in Sheffield were kept on the ward. The others were returned to their base unit under their own paediatrician's care. (This was invariably agreed to before the infant's transfer to Sheffield.)

Death occurred within nine months in all 25 (table V): three died within a week and $18(72 \%)$ by 3 months of age. Three infants lived for six months or longer. Two went home from the local hospital, and the third was unfortunately being tubefed for months before dying of oesophageal ulceration and aspirated vomit.

TABLE v-Age at Death in 25 Untreated Infants

\begin{tabular}{|c|c|c|c|c|c|c|c|c|c|c|}
\hline \multirow{7}{*}{$\begin{array}{l}\text { Alive at: } \\
1 \text { Day } \\
1 \text { Week } \\
1 \text { Month } \\
3 \text { Months } \\
6 \text { Months } \\
9 \text { Months }\end{array}$} & & & & & & & & & \multicolumn{2}{|c|}{ No. of Patients } \\
\hline & . & . & . & . & $\cdots$ & . & $\cdots$ & $\cdots$ & . & \\
\hline & $\ldots$ & . & $\ldots$ & $\ldots$ & $\cdots$ & $\ldots$ & $\ldots$ & $\ldots$ & .. & 22 \\
\hline & $\cdots$ & . & $\cdots$ & $\cdots$ & $\cdots$ & $\cdots$ & $\cdots$ & $\cdots$ & . & 14 \\
\hline & . & . & . & . & . & . & .. & .. & . & 7 \\
\hline & $\cdots$ & .. & . & $\cdots$ & . & . & $\ldots$ & . & .. & 2 \\
\hline & $\ldots$ & . & .. & . & . & .. & . & $\ldots$ & .. & 0 \\
\hline
\end{tabular}

The most common immediate cause of death was ventriculitis (10 infants), followed by the hydrocephalus itself (six infants); four died of associated congenital anomalies of the heart and other organs; respiratory infection was the last illness in three; but there is no definite information about the remaining two (table VI). Necropsy was carried out in 19 infants. All had multiple potential causes of death.

TABLE VI-Principal Cause of Death in 25 Untreated Infants

\begin{tabular}{|c|c|c|c|}
\hline & & $\begin{array}{r}\text { No. of } \\
\text { Patients }\end{array}$ & $\begin{array}{l}\text { Cause of Death } \\
\text { Proved by } \\
\text { Necropsy }\end{array}$ \\
\hline $\begin{array}{l}\text { Ventriculitis . } \\
\text { Hydrocephalus (with other congenital an } \\
\text { Respiratory ... } \\
\text { Congenital anomalies, including heart } \\
\text { Not known ... } \quad . .\end{array}$ & $\begin{array}{ll}\text {.omalies) } \\
\ldots \\
\cdots & \cdots \\
\cdots & \cdots\end{array}$ & $\begin{array}{r}10 \\
6 \\
3 \\
4 \\
2\end{array}$ & $\begin{array}{r}8 \\
4 \\
3 \\
4 \\
-\end{array}$ \\
\hline \multicolumn{2}{|l|}{ Total } & 25 & 19 \\
\hline
\end{tabular}

\section{Discussion}

The fear that some untreated severe cases of myelomeningocele might survive for long has not been substantiated, and so far the strict criteria for selection have proved 
reliable. The parents were invariably appreciative of the painless and humane nursing of their untreated infants. Everyone realizes that the solution offered by "selection" is not a good one. There is no "good solution" to a desperate, insoluble problem, merely a "least bad solution," which is being offered.

Selection has also led to an undoubtedly better quality of the survivors than was the case for the less severely affected infants in the past. None have "severe handicaps" so far, except the one treated infant who did have adverse criteria (thoracolumbosacral lesion) at birth. This shows the need for the utmost strictness in applying the criteria for selection.

The results in the untreated infants are similar to the larger series reported from Oxford, but where the decision not to treat was not based on exact criteria (Hide et al., 1972) and the subsequent management of the infants was not necessarily uniform. This may explain why $4 \%$ of the patients survived to two years of age.

One of the advantages of the proposed criteria for selection is that the infants are so severely affected at birth that no appreciable functional loss can result from failure to treat on the first day. On the contrary, at least their hydrocephalus is less likely to be rapidly progressive. If an occasional infant were to survive in good general condition for over six months and seemed likely to live, then he could be "brought back into the fold" and be treated for his hydrocephalus and for his renal, orthopaedic, and other problems as necessary.

If it is the open objective of "no treatment" that the infant should die soon and painlessly, then why cannot euthanasia be carried out? (Freeman, 1972). I wholly disagree with euthanasia. Though it is fully logical, and in expert and conscientious hands it could be the most humane way of dealing with such a situation, legalizing euthanasia would be a most dangerous weapon in the hands of the State or ignorant or unscrupulous individuals. One does not have to go far back in history to know what crimes can be committed if euthanasia were legalized. The best hope for the future is to discover the cause or causes of spina bifida and to prevent its occurrence. Already there is a chink of hope on the horizon, and the recent dramatic decline in the incidence of spina bifida in Sheffield (J. Lorber, unpublished data, 1973) gives us the hope that one day it will not be such a major problem for our children and their families.

I am grateful for the whole-hearted co-operation in this study to the numerous colleagues who referred cases under their care, to my own junior medical staff and my nurses who uphold and practise this policy, and especially to the parents whose active co-operation makes selection less difficult, though a far from easy task.

APPENDIX-Contraindications to Active Therapy

At birth:

(1) Gross paralysis of the legs (paralysis below 3rd lumbar segmental level

with at most hip flexors, adductors, and quadriceps being active).

(2) Thoracolumbar or thoracolumbosacral lesions related to vertebral

(3) Kyphosis or scoliosis.

(4) Grossly enlarged head, with maximal circumference of $2 \mathrm{~cm}$ or more Grossly enlarged head, with maximal circumfer
above the 90th percentile related to birth weight.

(5) Intracerebral birth injury

(6) Other gross congenital defects-for example, cyanotic heart disease, ectopia of bladder, and mongolism.

After closure, in the newborn period:

Meningitis or ventriculitis in an infant who already has serious neurological handicap and hydrocephalus.

Later:

In any life-threatening episode in a child who is severely handicapped by gross mental and neurological defects.

\section{References}

Collis, V. R. (1972). Developmental Medicine and Child Neurology, 14, Suppl. no. 27, p. 34.

Department of Health and Social Security (1973). Care of the Child with Spina Bifida. London, D.H.S.S.

Eckstein, H. B. (1973). British Medical Fournal, 2, 284.

Freeman, J. M. (1972). Fournal of Pediatrics, 80,904

Hide, D. W., Williams, H. P., and Ellis, H. L. (1972). Developmental Medicine and Child Neurology, 14, 304.

Lorber, J. (1971). Developmental Medicine and Child Neurology, 13, 279.

Lorber, Y. (1972 a). Archives of Disease in Childhood, 47, 854.

Lorber, J. (1972 b). Developmental Medicine and Child Neurology, 14, Suppl. No. 27, p. 87.

Medical Journal of Australia, 1971, 2, 1151.

Medical Journal of Australia, 1971, 2, 1151 . Archives of Disease in Childhood, 38, 18.

Stark, G. D., and Drummond, M. (1973). Archives of Diseases in Childhood, 48. 676 .

The Times, 21 August 1972, p. 11.
Zachary, R. B. (1968). Lancet, 2, 274. 